\title{
Zerumbone-loaded nanostructured lipid carriers: preparation, characterization, and antileukemic effect
}

This article was published in the following Dove Press journal:

International Journal of Nanomedicine

I August 2013

Number of times this article has been viewed

\author{
Heshu Sulaiman Rahman ${ }^{1-3}$ \\ Abdullah Rasedee ${ }^{1,2}$ \\ Chee Wun How ${ }^{2}$ \\ Ahmad Bustamam Abdul ${ }^{2}$ \\ Nazariah Allaudin \\ Zeenathul ${ }^{1,2}$ \\ Hemn Hassan Othman' \\ Mohamed Ibrahim Saeed ${ }^{2}$ \\ Swee Keong Yeap ${ }^{2}$ \\ 'Department of Microbiology and \\ Pathology, Faculty of Veterinary \\ Medicine, University Putra Malaysia, \\ Serdang, Selangor, Malaysia; ${ }^{2}$ Institute \\ of Bioscience, University Putra \\ Malaysia, Serdang, Selangor, Malaysia; \\ ${ }^{3}$ Department of Microbiology, Faculty \\ of Veterinary Medicine, University \\ of Sulaimanyah, Sulaimanyah City, \\ Kurdistan Region, Northern Iraq
}

Correspondence: Abdullah Rasedee; Heshu Sulaiman Rahman Department of Microbiology and Pathology, Faculty of Veterinary Medicine, University Putra Malaysia, 43400 UPM

Tel +60389463455

Fax +6038946 I07I

Email rasedee@vet.upm.edu.my; heshusr77@gmail.com
Serdang, Selangor, Malaysia

\begin{abstract}
Zerumbone, a natural dietary lipophilic compound with low water solubility $\left(1.296 \mathrm{mg} / \mathrm{L}\right.$ at $\left.25^{\circ} \mathrm{C}\right)$ was used in this investigation. The zerumbone was loaded into nanostructured lipid carriers using a hot, high-pressure homogenization technique. The physicochemical properties of the zerumbone-loaded nanostructured lipid carriers (ZER-NLC) were determined. The ZER-NLC particles had an average size of $52.68 \pm 0.1 \mathrm{~nm}$ and a polydispersity index of $0.29 \pm 0.004 \mu \mathrm{m}$. Transmission electron microscopy showed that the particles were spherical in shape. The zeta potential of the ZER-NLC was $-25.03 \pm 1.24 \mathrm{mV}$, entrapment efficiency was $99.03 \%$, and drug loading was $7.92 \%$. In vitro drug release of zerumbone from ZER-NLC was $46.7 \%$, and for a pure zerumbone dispersion was $90.5 \%$ over 48 hours, following a zero equation. Using the MTT (3-(4,5-dimethylthiazol-2-yl)-2,5-diphenyltetrazolium bromide) assay in human T-cell acute lymphoblastic leukemia (Jurkat) cells, the half maximal inhibitory concentration $\left(\mathrm{IC}_{50}\right)$ of ZER-NLC was $5.64 \pm 0.38 \mu \mathrm{g} / \mathrm{mL}$, and for free zerumbone was $5.39 \pm 0.43 \mu \mathrm{g} / \mathrm{mL}$ after 72 hours of treatment. This study strongly suggests that ZER-NLC have potential as a sustainedrelease drug carrier system for the treatment of leukemia.
\end{abstract}

Keywords: zerumbone, nanostructured lipid carrier, leukemia

\section{Introduction}

Zerumbone (Figure 1) is a crystalline, monocyclic, sesquiterpene, phytochemical substance that was first isolated as a major compound in 1960 from the essential volatile oil of edible wild ginger rhizomes, Zingiber zerumbet (L.) Smith. ${ }^{1,2}$ Zerumbone has been shown to possess antitumor, anti-inflammatory, antioxidant, antimicrobial, antinociceptive, hepatoprotective, and immunomodulatory activity. This compound also significantly suppresses tumor promoter 12-O-tetradecanoylphorbol-13-acetate-induced Epstein-Barr virus activation in Raji cells and free radical (superoxide anion) generation in cancer cell lines, and strongly inhibits platelet aggregation induced by arachidonic acid, collagen, and adenosine diphosphate. ${ }^{3-5}$ While zerumbone can modulate osteoclastogenesis induced by RANKL (receptor activator of nuclear factor-kappaB ligand), it cannot prevent cisplatininduced clastogenesis. ${ }^{6,7}$ Although zerumbone has been credited with much pharmacologic potential, its therapeutic application remains low because of poor water solubility.

Approximately $40 \%$ of drugs in the pipeline and $70 \%$ of synthetic therapeutic molecules are plagued with poor solubility, oral bioavailability, and delivery. 8,9 Drugs with poor solubility suffer from limited transport after oral administration because of a low concentration gradient between the gut and blood vessels. Similarly, when administered parenterally as microsuspensions, adequate drug levels cannot be achieved in body fluids because of limited solute concentrations at the injection site. ${ }^{10}$ New delivery methods need to be developed to increase the saturation solubility 


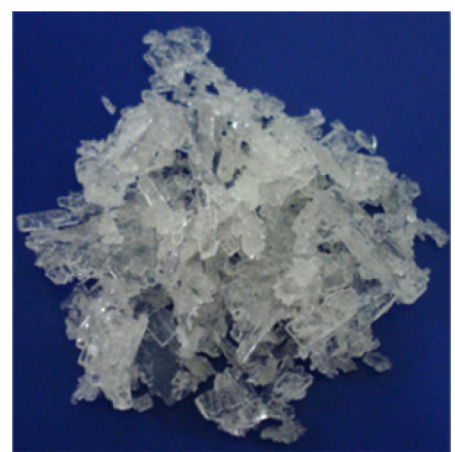

Figure I Pure zerumbone crystals.

of poorly soluble drugs in body fluids. ${ }^{11}$ One approach is to use solid lipids as nanocarriers to load these drugs, thereby improving their solubility. ${ }^{12,13}$ The effectiveness of these drug-loaded nanoparticles as a drug delivery system relies on their ability to penetrate several anatomic barriers, to show sustained-release characteristics, and be stable at a nanometer size. ${ }^{10,14}$ For this purpose, different types of nanocarriers, including solid lipid nanoparticles (SLN), nanostructured lipid carriers (NLC), and lipid-drug conjugates have been developed. ${ }^{15,16}$ Lipid nanoparticles form a carrier system with a number of desirable features, including low toxicity, a biodegradable particulate matrix, nontoxic degradation products, a high capacity to incorporate lipophilic and hydrophilic drugs, controlled release of the incorporated drug, and easy scale-up at low cost. ${ }^{17}$ NLC, which are new second-generation SLN, have all these properties and hold great promise as a controlled and site-specific drug delivery system that overcomes the disadvantages of SLN. ${ }^{18,19}$ Among the notable advantages of NLC over SLN include their greater flexibility in drugloading and drug-holding, which is essential for long-term stability and modulation of drug release. ${ }^{20,21}$ Nanostructured lipid carriers are composed of a solid lipid matrix blended and firmly incorporated with liquid lipids (oils) that allow the total lipid content to be increased to as high as $95 \%$. $^{22,23}$ The technique used to prepare NLC is high-pressure homogenization, which produces highly viscous, gel-like, or pasty NLC dispersions. ${ }^{24,25}$

In an attempt to determine the therapeutic effect of zerumbone-loaded nanostructured lipid carriers (ZER-NLC), we chose a human T-cell acute lymphoblastic leukemia (Jurkat) cell line as the target. Currently, the mechanism by which ZER-NLC affects leukemia cells is not known. Therefore, the objective of this study was to produce ZERNLC and to determine their physiochemical properties and effect on proliferation in a Jurkat cell line.

\section{Materials and methods Materials}

The reagents and chemicals used in this study were of analytical grade, and included hydrogenated palm oil (SigmaAldrich, St Louis, MO, USA), olive oil (Sigma-Aldrich), lipoid S100 (lecithin or phosphatidylcholine) (Sigma-Aldrich), sorbitol (Sigma-Aldrich), Tween-80 (polysorbate-80, Fisher Scientific, Waltham, MA, USA), and thimerosal (SigmaAldrich). Double-distilled water (Aquatron Inc, Boca Raton, FL, USA) was used in all experiments.

\section{Extraction of zerumbone}

Pure colorless zerumbone crystals were prepared from the extracted essential oil of fresh Z. Zerumbet rhizomes by steam hydrodistillation according to a method described earlier ${ }^{26}$ and yielded $1.3 \mathrm{~g} / \mathrm{kg}$ rhizome. In brief, fresh rhizomes were initially cleaned, washed, sliced, and then placed in a steam distillator containing tap water and heated. The outlet of the device was connected to Dienstag glassware in order to collect the distillate containing volatile oil. The volatile oil was spontaneously crystallized using absolute n-hexane $100 \%$ (Sigma-Aldrich) and the solution was then left to evaporate in a fume hood (Novaire, Newton, MA, USA). Recrystallization was performed three times, also using absolute n-hexane $(100 \%)$ to obtain pure zerumbone crystals. The purity of zerumbone determined using a high performance liquid chromatography (HPLC) system (Waters, Milford, MA, USA) was $99.96 \%$. Pure zerumbone crystals were collected in clean glass vials and kept at $4^{\circ} \mathrm{C}$ until further analysis.

\section{Preparation of lipid dispersion}

The lipid phase was composed of hydrogenated palm oil, olive oil, and lipoid S100 at a ratio of 7:3:3 and was melted by heating to approximately $10^{\circ} \mathrm{C}$ above the melting point of the lipid matrices to avoid any lipid memory effect. Four hundred milligrams of zerumbone was then added to the molten lipid, which was yellowish-milky in color.

\section{Preparation of aqueous dispersion}

Sorbitol $4.75 \mathrm{~g}$, Tween- $801.0 \mathrm{~g}$, and thimerosal $0.005 \%$ were dissolved in double-distilled water and made up to $100 \mathrm{~mL}$. This aqueous surfactant solution was then heated with stirring to the same temperature as the lipid matrices.

\section{Preparation of NLC emulsion}

Zerumbone $(0.4 \%, \mathrm{w} / \mathrm{v})$ in lipid melt was dispersed in the aqueous surfactant solution to obtain hot pre-emulsions by high-speed stirring in an Ultra-Turrax ${ }^{\circledR}$ (IKA Werke GmbH 
and Co, Staufen, Germany) at 13,000 rpm for 10 minutes. The hot pre-emulsions were then homogenized in a highpressure homogenizer (EmulsiFlex ${ }^{\circledR}$, Avestin Inc, Ottawa, ON, Canada) at 1,000 bar for 20 cycles at $60^{\circ} \mathrm{C}$. The hot oil-in-water nanoemulsion was immediately transferred to siliconized glass vials, sealed, and allowed to undergo lipid phase crystallization at room temperature $\left(25^{\circ} \mathrm{C}\right)$ for formation of ZER-NLC (Figure 2).

\section{Characterization of ZER-NLC}

Adequate and proper characterization of the NLC was necessary to determine quality. For the ZER-NLC, the parameters analyzed were particle size, size distribution kinetics (zeta potential), degree of crystallinity and lipid modification (polymorphism), coexistence of additional colloidal structures, time scale of distribution, drug content and stability, in vitro drug release, and morphology. ${ }^{11,27}$

\section{Particle size and polydispersity index}

Photon correlation spectroscopy, also known as dynamic light scattering, is the most powerful technique for routine measurement of particle size and distribution of nanoparticle width. The aqueous ZER-NLC were dispersed in a fixed amount of filtered double-distilled water and placed in a disposable cuvette (Malvern, UK). From the analysis, the mean particle size (diameter, $\mathrm{nm} \pm$ standard deviation) and polydispersity index (size distribution) of ZER-NLC were calculated using Malvern software (Zetasizer Nano ZS, Malvern, UK). The measurements were carried out in triplicate, and standard deviations were calculated at a fixed scattering angle of $90^{\circ}$ at room temperature $\left(25^{\circ} \mathrm{C}\right) .{ }^{28}$

\section{Measurement of zeta potential}

Zeta potential is an indirect measurement of the thickness of the diffusion layer and is used to predict long-term stability.

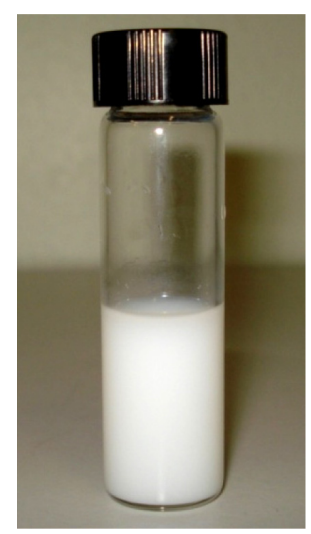

Figure 2 Appearance of zerumbone-loaded nanostructured lipid carriers.
The particle electrophoretic movement was measured using the laser Doppler electrophoresis technique and the zeta potential was determined using the Zetasizer Nano ZS. The measurements were conducted in triplicate after appropriate dilution of freshly prepared particles in double-distilled water to obtain the optimum kilocounts per second of 50-200 for measurement. ${ }^{29}$

\section{Transmission electron microscopy}

Transmission electron microscopy was used to determine the shape and surface morphology of the nanoparticles. A drop of the diluted ZER-NLC dispersion was placed on the surface of a carbon-coated copper grid after removal of excess liquid using a hydrophilic filter membrane. On drying at $25^{\circ} \mathrm{C}$ for up to one minute, the grid with a mesh size of 300 was then negatively stained with $2 \%$ phosphotungstic acid (w/v) for one minute and allowed to dry at room temperature. ${ }^{30}$ The ZER-NLC sample was placed onto a sample holder, probed using a transmission electron microscope (Hitachi H-7100, Tokyo, Japan) and the image captured.

\section{Lyophilization of ZER-NLC}

Lyophilization is the best way to increase the physical and chemical stability of nanoparticles for long-term storage and improved incorporation into pellets, tablets, and capsules. Lyophilized ZER-NLC were prepared for differential scanning calorimetry and wide-angle X-ray diffraction screening using a freeze dryer (Martin Christ $\mathrm{GmbH}$, Osterode am Harz, Germany). Briefly, $8 \mathrm{~mL}$ of ZER-NLC dispersion was poured into a plastic Petri dish and frozen at $-80^{\circ} \mathrm{C}$ (Thermoforma, Marlotta, USA). The plate was then wrapped in parafilm with several holes punched into the cover and subsequently freeze-dried for 24 hours at $-55^{\circ} \mathrm{C} .{ }^{31}$

\section{Differential scanning calorimetry}

Differential scanning calorimetry is used to determine the speciation of crystallinity and polymorphism of bulk materials, drugs, and drug nanoparticles by measurement of glass and melting point temperatures at their respective enthalpies. ${ }^{27}$ The thermal characteristics of the hydrogenated palm oil, zerumbone, and lyophilized ZER-NLC were determined using a differential scanning calorimeter (822e, Mettler Toledo, Greifensee, Switzerland). Approximately $10 \mathrm{mg}$ of bulk lipid, zerumbone, and lyophilized ZER-NLC were placed in pin-hole bottom sealed aluminum pans with lids and heated. An empty aluminum pan was used as the reference. Differential scanning calorimetric curves were recorded across a temperature range of $20^{\circ} \mathrm{C}-80^{\circ} \mathrm{C}$, 
with a constant linear heating rate of $5^{\circ} \mathrm{C}$ per minute in pure ultrahigh dry nitrogen. The analysis was repeated three times and values are expressed as the mean of three determinations. Finally, the enthalpies were calculated using the Mettler Star software. $^{32}$

\section{Wide-angle $X$-ray diffraction}

The geometric scattering of radiation from crystal planes within a nanoparticle dispersion can be determined by wideangle X-ray diffraction to assess the degree of crystallinity. An X-ray diffractometer (Philips, Hamburg, Germany), equipped with a copper anode $(\gamma=1.5406 \AA)$ for radiation was used to detect the crystallinity of the lyophilized ZER-NLC. Powdered samples of hydrogenated palm oil, zerumbone, and lyophilized ZER-NLC about $10 \mathrm{~mm}$ in length were placed on the top of X-ray plates, exposed to a voltage of $45 \mathrm{kV}$ and a $40 \mathrm{~mA}$ current at room temperature, with a scanning speed of $5^{\circ}$ per minute and a scanning range of $2 \theta$. The X-ray diffractogram patterns were recorded over the range of $20^{\circ}-80^{\circ} .3^{33}$

\section{Stability}

To monitor the short-term stability of ZER-NLC as a function of storage conditions, $5.0 \mathrm{~mL}$ volume samples of the ZER-NLC dispersion were placed in amber-colored glass vials three days after preparation. The vials were stored at temperatures of $4^{\circ} \mathrm{C}, 25^{\circ} \mathrm{C}$, and $40^{\circ} \mathrm{C}$. After 30 days, the average particle size, polydispersity index, zeta potential, entrapment efficiency, and $\mathrm{pH}$ values of the nanoparticles were determined. The analysis was done in triplicate. ${ }^{34,35}$

\section{$\mathrm{pH}$ measurements}

A calibrated pH meter (model S47-K, Mettler Toledo, Beaumont Leys, UK) was used each week to determine the $\mathrm{pH}$ of the ZER-NLC at room temperature, from the first day of production through to 5 weeks.

\section{Sterilization by autoclaving}

To observe the effect of sterilization on the particle size, zeta potential, and entrapment efficiency of ZER-NLC, about $5.0 \mathrm{~mL}$ of ZER-NLC was autoclaved at $121^{\circ} \mathrm{C}$ and $15 \mathrm{psi}$ for 20 minutes. ${ }^{36}$

\section{High performance liquid chromatography Preparation of zerumbone stock solution}

One milligram of zerumbone was weighed (ALPS-AL204, Mettler Toledo, UK) and diluted to $1.0 \mathrm{~mL}$ with absolute methanol (Sigma-Aldrich) in a $10 \mathrm{~mL}$ conical flask. A series of standard working solutions for zerumbone were prepared at concentrations of $2.5,5,10,20$, and $40 \mu \mathrm{g} / \mathrm{mL}$.

\section{HPLC conditions}

HPLC determination was done in a validated reverse phase HPLC system consisting of a mobile phase delivery pump, autosampler, ultraviolet detector, and a workstation (Waters Alliance, Milford, MA, USA). A stainless steel, $4 \mu \mathrm{m}$ particle size $(4.6 \mathrm{~mm}$ internal diameter $\times 100 \mathrm{~mm}$ length) analytical symmetry column (Merck, Darmstadt, Germany) packed with a dimethyl octylsilyl (C18)-bonded amorphous silica stationary phase was used. The mobile phase composed of a binary mixture of HPLC grade absolute methanol and potassium dihydrogen phosphate buffer $0.001 \%(\mathrm{pH} 6)$ at a ratio of 70:30 (v/v), which was freshly prepared for each run and degassed before use. The column temperature was set to $50^{\circ} \mathrm{C}$ (ambient temperature). The injection volume was $10 \mu \mathrm{L}$, with a flow rate of $1 \mathrm{~mL}$ per minute. The samples were estimated by ultraviolet detection at a wavelength of $250 \mathrm{~nm}$.

The reverse phase HPLC system was calibrated with standard zerumbone solutions of $2.5-40.0 \mu \mathrm{g} / \mathrm{mL}$. Zerumbone samples were chromatographed at room temperature and eluted for 2.206 minutes. A calibration curve was plotted, and a good linear relationship was observed between the concentration of zerumbone and peak area of zerumbone, with an acceptable correlation coefficient $\left(r^{2}=0.998\right)$ for quantitative analysis. This calibration is required to determine the precision and accuracy of the HPLC method. ${ }^{37}$

\section{Entrapment efficiency and drug-loading capacity}

The amount of drug incorporated into the NLC influences drug-release characteristics, so it is very important to be able to estimate the quantity of encapsulated drug per unit weight of nanoparticles. ${ }^{16}$ The entrapment efficiency and drug loading of ZER-NLC were estimated after separation of free zerumbone and solid lipids from the aqueous medium by ultrafiltration. For this purpose, we used Centrisart ${ }^{\circledR}$ filter tubes (Sartorius AG, Göttingen, Germany) consisting of a filter membrane (molecular weight cutoff $300 \mathrm{kD}$ ) at the base of the sample recovery chamber. A $3 \mathrm{~mL}$ sample of undiluted ZER-NLC was placed in the outer chamber and the sample recovery chamber was fitted on top of the sample. The unit was closed and centrifuged at $20,000 \times \mathrm{g}$ for 15 minutes (Zentrifugen 32, Andreas Hettich $\mathrm{GmbH}$ and $\mathrm{Co}, \mathrm{KG}$, Tuttlingen, Germany). The principle behind this process is based on ZER-NLC remaining in the outer chamber separated from the aqueous phase while the aqueous phase filters 
into the sample recovery chamber through the membrane. The amount of zerumbone in the aqueous phase was then evaluated by validated HPLC. The amount of zerumbone in the NLC was calculated according to the method of Wa Kasongo et al, ${ }^{32}$ ie, calculating the difference between the total amount of dispersion and the amount of zerumbone remaining in aqueous phase following ultrafiltration. volume with fresh phosphate-buffered solution to maintain constant and equal volumes throughout the study. ${ }^{40}$ The samples were analyzed by HPLC to determine the amount of zerumbone released from the NLC. The experiment was conducted in triplicate and the drug release data were evaluated by zero-order, first-order, and Higuchi equations to determine the release kinetics. ${ }^{41}$

Entrapment efficiency $(\mathrm{EE}) \%=\frac{(\text { Total amount of zerumbone }) \times(\text { Free amount of zerumbone })}{\text { Total }} \times 100$

Total amount of zerumbone

The following equation was used for determining the percent drug loading capacity of ZER-NLC ${ }^{30}$

Drug loading (DL)\%

$=\frac{\text { Total amount of zerumbone encapsulated into NLC }}{\text { Total amount of lipid used in ZER-NLC formulation }} \times 100$

\section{In vitro drug release study}

An in vitro drug release study is useful for determination of quality and prediction of the behavior of ZER-NLC in vivo. Release of zerumbone from the NLC was allowed to proceed for 48 hours using an in vitro kinetic method involving dispersion of lipid nanoparticles in the release medium. The characteristics of zerumbone release from the NLC were determined using a modified Franz diffusion cell system (Permgear, Heller town, PA, USA) with a surface area of $0.785 \mathrm{~cm}^{2}$ and a capacity of $5 \mathrm{~mL}$. A cellulose acetate membrane (pore size $200 \mathrm{~nm}$, molecular weight cutoff $5-10 \times 10^{3} \mathrm{Da}$ ) sourced from HiMedia (Mumbai, India) was inserted between the donor and receptor compartments using a rubber ring. ${ }^{38,39}$ The membrane was first soaked in phosphate-buffered saline for 12 hours before mounting in the Franz diffusion cell. Next, $0.5 \mathrm{~mL}$ of ZER-NLC (vehicle) or $0.5 \mathrm{~mL}$ of zerumbone in dimethyl sulfoxide solution (control) was loaded into the donor compartment. The concentration of zerumbone in both cases was $4.0 \mathrm{mg} / \mathrm{mL}$. The receptor compartment was filled with $5 \mathrm{~mL}$ of dialysis medium $(0.1 \mathrm{M}$ phosphatebuffered saline $\mathrm{pH} 7.4$ and sodium dodecyl sulfate $2 \%$, Sigma-Aldrich) to maintain sink conditions during the experiment. The content of the cell was agitated continuously using a magnetic stirrer at $500 \mathrm{rpm}$ and a constant temperature $\left(37.0^{\circ} \mathrm{C} \pm 0.5^{\circ} \mathrm{C}\right)$. A $500 \mu \mathrm{L}$ sample was removed from the medium in the receptor compartment through a side-arm tube using a stainless steel 316 syringe needle (Sigma-Aldrich) at 0.5, 1, 2, 4, 6, 8, 10, 12, 24, and 48 hours. All samples withdrawn were brought to the same

\section{In vitro cytotoxic study}

Cell culture

A human T-cell acute lymphoblastic leukemia (J.RT3-T3.5) cell line, commonly known as the Jurkat cell line, was purchased from American Type Culture Collection (ATCC, Manassas, VA, USA). The cells were maintained and grown in Roswell Park Memorial Institute (RPMI)-1640 medium from ATCC, and supplemented with L-glutamine $(2 \mathrm{mM})$, $10 \%$ heat-inactivated fetal calf serum (ATCC), 100 units $/ \mathrm{mL}$ penicillin, and $100 \mu \mathrm{g} / \mathrm{mL}$ streptomycin (Sigma-Aldrich).

\section{Cytotoxicity assay}

The antiproliferative effect of zerumbone, zerumbone-free NLC (blank nanoparticles), and ZER-NLC on the Jurkat T-cells was quantified by MTT (3-(4,5-dimethylthiazol-2yl)-2,5-diphenyltetrazolium bromide) assay, as described elsewhere. ${ }^{42}$ The zerumbone stock and working solutions were prepared using dimethyl sulfoxide solution (Sigma-Aldrich) and RPMI-1640 complete growing medium, respectively, whilst the ZER-free NLC and ZER-NLC working solutions were prepared with RPMI-1640 complete growing medium. The Jurkat T-cells were allowed to grow in a $75 \mathrm{~cm}^{2}$ cell culture flask until confluent, and the cell density was determined using a hemocytometer. A cell suspension containing about $2 \times 10^{5}$ cells $/ \mathrm{mL}$ was then seeded into each well of 96 -well microculture plates (Techno Plastic Products AG, Trasadingen, Switzerland). Simultaneously, the cells were treated with either zerumbone, blank nanoparticles, and ZER-NLC at various concentrations in the 96-well microculture plates. After incubation for 24, 48, and 72 hours in a $\mathrm{CO}_{2}$ incubator at $37^{\circ} \mathrm{C}$, MTT (microculture tetrazolium, Sigma-Aldrich) solution $(5 \mathrm{mg} / \mathrm{mL})$ in $\mathrm{pH} 7.4$ phosphate-buffered solution (Sigma-Aldrich) was added into each well, covered with aluminum foil, and incubated for a further 4 hours in the dark to allow formation of water-insoluble purple formazan. The media were aspirated and remaining purple formazan was lysed with MTT solubilization solution (Sigma-Aldrich) with shaking for 5 minutes. The absorbance 
was determined in an enzyme-linked immunosorbent assay universal plate reader (Bio-Tek Instruments Inc, Winooski, VT, USA) at $570 \mathrm{~nm}$ after background correction at $630 \mathrm{~nm}$. The half maximal inhibitory concentration $\left(\mathrm{IC}_{50}\right)$ value (concentration at which $50 \%$ of cells are killed) was determined from the dose-response curve. Finally, the antiproliferative effect of ZER-NLC was compared with that of zerumbone (positive control) and zerumbone-free NLC.

\section{Statistical analysis}

The data obtained were statistically analyzed, and the results expressed as mean \pm standard deviation. One-way analysis of variance was performed using Statistical Package for the Social Sciences version 17.0 software (SPSS Inc, Chicago, IL, USA) to calculate $\mathrm{r}^{2}$ for zero order kinetics.

\section{Results and discussion}

Formulation of poorly soluble drugs in aqueous and organic media is generally an intractable issue in the pharmaceutical field. A nanodelivery system such as NLC can be the solution to the solubility problem while serving as a vehicle with enhanced drug-loading capacity.

\section{Particle size and polydispersity index}

Mean particle size and the polydispersity index are important features of NLC, from which the stability of these nanoparticles when drug-loaded can be predicted. The mean particle size and polydispersity index of the ZER-NLC produced in this study were $52.68 \pm 0.1 \mathrm{~nm}$ and $0.29 \pm 0.0041 \mu \mathrm{m}$, respectively.

Particle size can influence the distribution of nanoparticles, because a small particle size leads to a narrow polydispersity index and vice versa. A small particle size is an advantage for ZER-NLC because it decreases uptake by the liver, prolongs circulation time in the blood, and improves bioavailability. ${ }^{43}$ Small particles are also minimally phagocytosed by macrophages, so destruction and clearance by the body is minimized. ${ }^{44}$ In this study, the morphology of ZER-NLC was determined by transmission electron microscopy within 7 days of production. As seen in Figure 3, the ZER-NLC were nanometer size, round to spherical and relatively uniform in shape, and had a narrow size distribution. However, upon measurement using photon correlation spectroscopy, the sizes of the ZER-NLC were shown to be smaller than those obtained by transmission electron microscopy. The discrepancy in size distribution obtained by the two methods may be attributed to differences in measurement principles, measuring conditions, and the methods used. Using photon correlation spectroscopy, measurement of particle size is

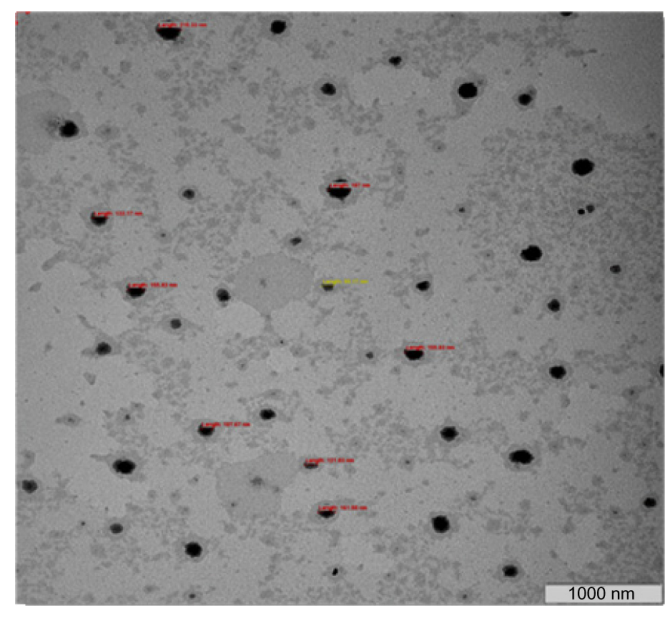

Figure 3 Transmission electron microscopic image of zerumbone-loaded nanostructured lipid carriers.

based on Brownian displacement, whereas using transmission electron microscopy, measurement is based on exposure to a high vacuum electron beam column. ${ }^{45}$

\section{Zeta potential}

Particles in a nanosuspension show a negative charge on their surface, which is expressed as the zeta potential. The zeta potential is a key factor in prediction and evaluation of the stability of a colloidal dispersion. For full electrostatic stabilization, the zeta potential must be greater than $+30 \mathrm{mV}$ or less than $-30 \mathrm{mV}^{46} \mathrm{In}$ our study, the zeta potential for the ZERNLC was $25.03 \pm 1.24 \mathrm{mV}$, suggesting that these particles are quite stable. Generally, zeta potential measurements are based on the electrophoretic mobility of a drug in aqueous medium. Suspensions with a higher zeta potential appear to allow less particle flocculation and aggregation due to electrostatic repulsion. However, several experiments have demonstrated that not only electrostatic repulsion but also the use of steric stabilizers during preparation of nanoparticles determines the stability of a nanoparticle dispersion. Further, the zeta potential of NLC is independent of the lecithin content in the lipid matrix at a constant emulsifier concentration in the aqueous phase. ${ }^{11}$

\section{Crystallinity and polymorphism}

Differential scanning calorimetry is the most sensitive method for detecting nanoparticle crystallization via determination of melting temperature and heat flow, which are associated with material transition. Generally, lipid molecules exhibit three different polymorphic structures, ie, the unstable $\alpha^{-}$, the metastable $\beta$, and the most stable $\beta$-modification. The $\beta$-modification is prominently exhibited by most bulk lipids. ${ }^{47}$ 
The differential scanning calorimetry thermograms for hydrogenated palm oil, zerumbone, and lyophilized ZERNLC are shown in Figure 4. From the thermal curves, the hydrogenated palm oil, zerumbone, and ZER-NLC had endothermic peaks at $59.42^{\circ} \mathrm{C}, 66.40^{\circ} \mathrm{C}$, and $57.09^{\circ} \mathrm{C}$, respectively. This indicates that the bulk lipid in hydrogenated palm oil and ZER-NLC was in $\beta$-modification arrangement. ${ }^{48}$ The melting temperature of ZER-NLC was lower than that of hydrogenated palm oil, and this may be due to the presence of surfactants in the ZER-NLC. Depression in the melting point of nanosuspensions may also be due to a less ordered arrangement, requiring a lesser amount of

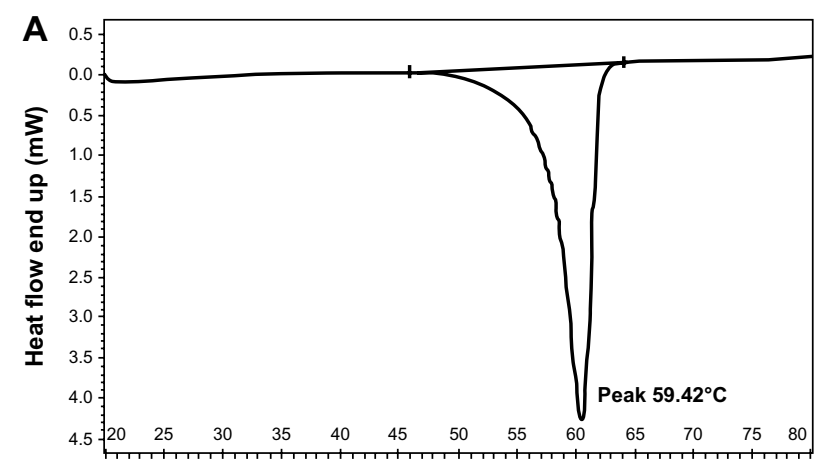

Temperature $\left({ }^{\circ} \mathrm{C}\right)$
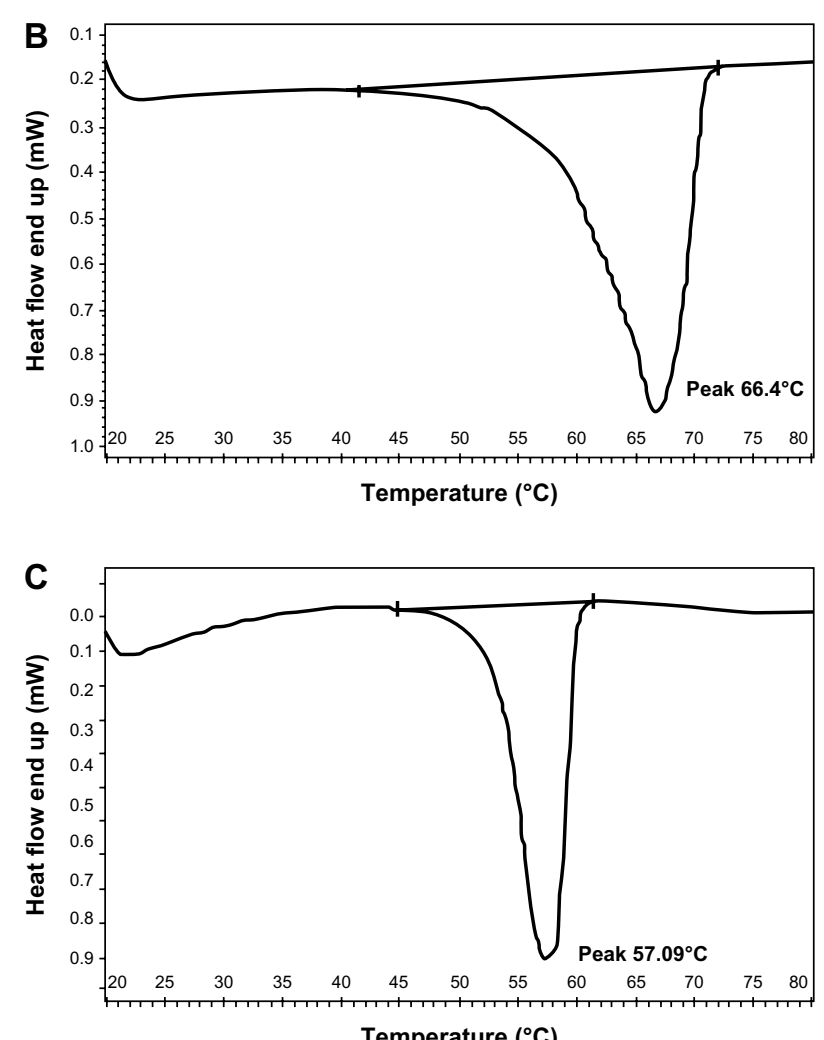

Figure 4 Differential scan thermograms of (A) hydrogenated palm oil, (B) zerumbone, and $(\mathbf{C})$ zerumbone-loaded nanostructured lipid carriers. energy to overcome the lattice force within the materials. ${ }^{49}$ Generally, the melting points of a colloidal system may decrease by $10^{\circ} \mathrm{C}-15^{\circ} \mathrm{C}$, because colloidal particles have a large surface to volume ratio. The apparent reduction in melting point of colloid formulations is not associated with particle size. ${ }^{50}$

\section{Wide angle $X$-ray diffraction}

Wide angle X-ray diffraction is an analytical tool complementary to differential scanning calorimetry in the assessment of degree of crystallinity and polymorphism of a bulk lipid, drug, and NLC. ${ }^{51}$ Thus, the wide angle X-ray diffractogram parallels results obtained by differential scanning calorimetric thermal analysis.

The X-ray diffraction patterns for pure zerumbone, hydrogenated palm oil, and ZER-NLC are shown in Figure 5, and indicate that zerumbone produced a diffraction pattern with a distinctive sharp peak, suggesting a crystalline structure. Similarly, a relatively sharp peak was observed for hydrogenated palm oil, although of lesser intensity. However, the diffraction peaks for ZER-NLC were broader, less intense, and showed more diffuse $\mathrm{X}$-ray scattering than hydrogenated palm oil, indicating that ZER-NLC is amorphous. There was no peak in the X-ray diffraction pattern for ZER-NLC, which resembled either pure crystalline zerumbone or hydrogenated palm oil. This indicates that, upon incorporation into NLC, zerumbone no longer retains its crystallinity and becomes amorphous. The lack of crystalline structure in the ZER-NLC would decrease the tendency for expulsion of the encapsulated drug during storage, hence favoring high drug-loading capacity. ${ }^{52}$

\section{Stability}

The particle size, polydispersity index and zeta potential of ZER-NLC increased to $92.11 \pm 0.25 \mathrm{~nm}, 0.53 \pm 0.025$ $\mu \mathrm{m}$ and $-20.43 \pm 0.41 \mathrm{mV}$ respectively, and entrapment efficiency was lowered to $94.53 \%$ after one month of storage at $40^{\circ} \mathrm{C}$. However, only very slight changes in mean particle size, polydispersity index, zeta potential, and entrapment efficiency was found in samples stored at $4^{\circ} \mathrm{C}$ and left to stand at room temperature prior to analysis. This implies that ZER-NLC stored either refrigerated or at room temperature are physically stable and do not flocculate or coalesce under these conditions. On the other hand, the $\mathrm{pH}$ of the ZER-NLC suspension decreased to 3.7 for samples stored at $40^{\circ} \mathrm{C}$, while the $\mathrm{pH}$ of those stored in refrigerated conditions and at room temperature were approximately 2.1 and 2.5 , respectively. This suggests that the $\mathrm{pH}$ of nanosuspensions will decrease 


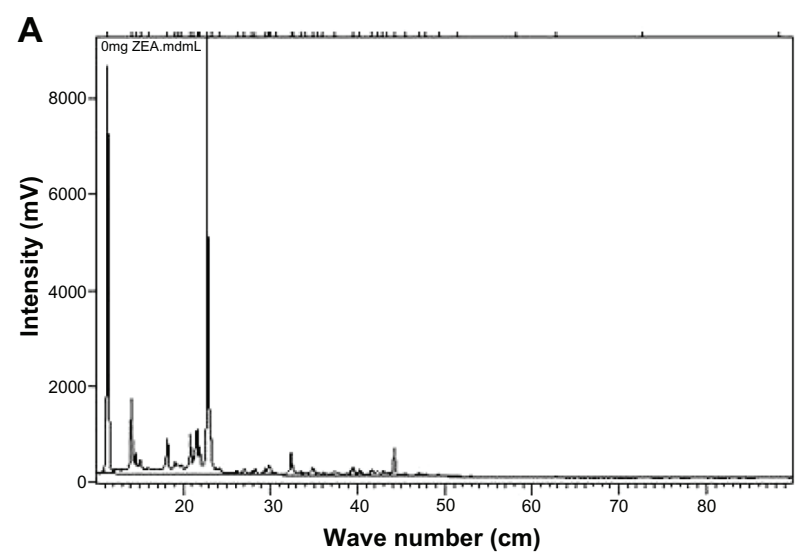

B
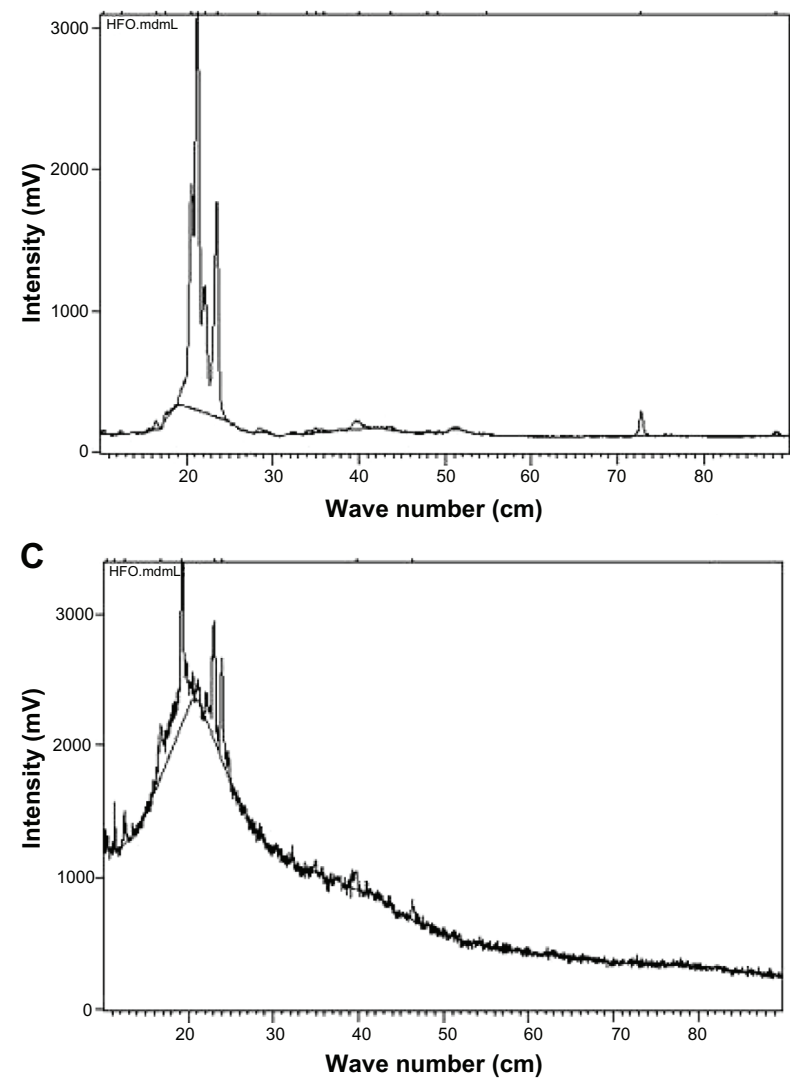

Figure 5 Powder x-ray diffraction patterns of (A) zerumbone, (B) hydrogenated palm oil, and (C) zerumbone-loaded nanostructured lipid carriers.

substantially as a function of time and temperature during storage, leading to degradation and liberation of free fatty acids, possibly as a result of glyceride and phosphatide degradation and hydrolysis. ${ }^{53}$ Under this circumstance, the decrease in $\mathrm{pH}$ can be controlled by adjusting the initial $\mathrm{pH}$ of the nanosuspension that should minimize hydrolysis of phospholipids and triglycerides. Therefore, to ensure stability of a ZER-NLC suspension, its $\mathrm{pH}$ should be monitored regularly during storage to ascertain that there is no release of free fatty acids from the nanoparticles.
It is possible that particle size may not be affected by temperature during the first month of storage. Particle size also seemed not to be affected by the experimental methods, which included high-speed centrifugation, filtration, freezedrying, and diluting buffer solutions at different $\mathrm{pH}$ values. This shows that the physical characteristics of aqueous ZERNLC dispersions were indeed stable, although transitions of dispersed lipid from a metastable to a stable form may occur slowly on storage and cause expulsion of the compound from solid lipid nanoparticles. ${ }^{36}$

\section{$\mathrm{pH}$}

The physical and chemical stability of nanosuspensions is dependent on $\mathrm{pH}$. Generally, the optimum $\mathrm{pH}$ of freshly prepared nanosuspensions is approximately 7.2 , which allows ionization of the phosphate groups at the surface of the lecithin to produce an optimum surface charge for the oil globules. Ultimately, there is an optimum $\mathrm{pH}$ range at which hydrolysis of lecithin is minimal. A pH lower than 5.0 should be avoided because electrostatic repulsion between the emulsified oil globules is decreased and the globules tend to coalescence and increase in size. In this study, the $\mathrm{pH}$ of the ZER-NLC suspension decreased markedly from day 1 until the end of week 5 when stored at room temperature. The $\mathrm{pH}$ change was mainly due to degradation of the lipid nanoparticles, which eventually led to formation of free fatty acids and a gradual reduction in $\mathrm{pH}$ of the nanosuspension. ${ }^{54}$

\section{Sterilization}

Application of heat could cause the NLC suspension to disintegrate. In our study, 20 minutes of sterilization using steam at $121^{\circ} \mathrm{C}$ affected the ZER-NLC by dramatically increasing the size of the particles by almost eight times their presterilization size, but they still remained within the nanosize range. Sterilization did not affect the entrapment efficiency but decreased the $\mathrm{pH}$ to 3.7. Because the $\mathrm{pH}$ of the nanosuspension decreased during heating, it is suggested that before instituting terminal heat sterilization the $\mathrm{pH}$ should first be adjusted to approximately 8.0. ${ }^{55}$ Sterilization causes hydrolysis of the lipids and lecithins present in the nanosuspension, resulting in liberation of free fatty acids, which lowers the $\mathrm{pH}$ of the suspension. Therefore, it is suggested that a nanoparticle suspension intended for parenteral administration be sterilized at $110^{\circ} \mathrm{C}$ for 40 minutes. Autoclaving has no effect on nanoparticle stability, but because it has an impact on particle size, nonheat sterilization may be used instead in the preparation of drug-loaded NLC. 
A ZER-NLC suspension with Tween- 80 as the stabilizer is a potentially excellent carrier for parenteral drug administration. The amount of emulsifier used should be optimal to ensure the entire surface of the nanoparticle is covered. The type of surfactant used in the NLC formulation will not affect particle size distribution, but it will affect its physicochemical properties, especially its crystallization characteristics, by generating different polymorphic forms. A high surfactant mixture using Tween- 80 can easily compensate for the missing electrostatic repulsion and provide long-term steric stability to the NLC. ${ }^{46}$

Nanosuspensions are affected by direct sunlight and temperature exceeding $30^{\circ} \mathrm{C}$ could possibly cause oxidative degradation. ${ }^{54}$ To ensure long-term stability of the NLC suspension, physical changes in the preparation, particularly drug precipitation and color change, can be determined by visual examination.

\section{Entrapment efficiency and drug loading}

Partitioning of a drug between lipid and water phases during pre-emulsion formation affects drug entrapment in nanoparticles. Drug partitioning is dependent on the amount of lipid, solubility of the drug in lipid, processing temperature, and surfactant concentration. ${ }^{55}$ The current study showed that when $400 \mathrm{mg}$ of zerumbone was used to load the NLC, approximately $3.88 \mathrm{mg}$ of free zerumbone was detected in an aqueous ZER-NLC dispersion, suggesting that $396.12 \mathrm{mg}$ $(99.03 \%, w / w)$ of zerumbone was successfully encapsulated into the NLC. The high entrapment efficiency of the nanosuspension is due to the high lipophilicity and low water solubility of zerumbone. Entrapment efficiency is an important parameter in the determination of drug-release characteristics, so its determination is an integral part of formulation development. In general, drug solubility is higher in a liquid than in a solid lipid, as shown by increased entrapment efficiency. ${ }^{56}$ Incorporation of liquid into solid lipids causes reduced crystallinity and more imperfections in the crystal lattice. These imperfections provide sufficient space within the nanosuspension particles to accommodate drug molecules, which in turn results in improved drug loading and entrapment efficiency ${ }^{54}$ To ensure sufficient drug loading, the drug must be formulated to be highly soluble in lipid melts. With NLC, to achieve a high entrapment efficiency, the lipid concentration of the dispersion must be decreased. The lipophilic components of the liquid lipids have greater solubility than those of solid lipids, which allows for more flexibility in modulation of both drug release and drug-loading efficiency. ${ }^{36}$ Therefore, the $7.92 \%$ loading capacity of ZER-NLC observed in this study is probably due to the high solubility of zerumbone in hydrogenated palm oil and olive oil.

\section{In vitro drug release study}

Our in vitro release study was performed using the dialysis technique. Data obtained from this study were fitted to various kinetic equations to determine the mechanism of zerumbone release from a ZER-NLC dispersion concurrently with the dispersion of pure zerumbone for 48 hours. ${ }^{30}$

The dialysis medium in the receptor compartment contained $2 \%$ sodium dodecyl sulfate as a solvent because it is hydrophobic and has poor solubility in aqueous medium. ${ }^{57}$ Dimethyl sulfoxide was used as the solvent in the donor compartment for the control group. This study showed that the in vitro drug release kinetics of zerumbone from NLC across the cellulose acetate membrane closely followed the zero-order kinetic model $\left(r^{2}=0.92\right)$. The cumulative percentage profiles of zerumbone released from the ZER-NLC dispersion and a dispersion of pure zerumbone over 48 hours are shown as in Figure 6, indicating that the zerumbone in the ZER-NLC was released gradually over the given period, while the control showed more rapid release of zerumbone than ZER-NLC. The amount of zerumbone released at the end of the 48-hour period from the NLC formulation was found to be $46.7 \%$ $(0.95 \mathrm{mg})$, indicating that the nanosuspension could be a
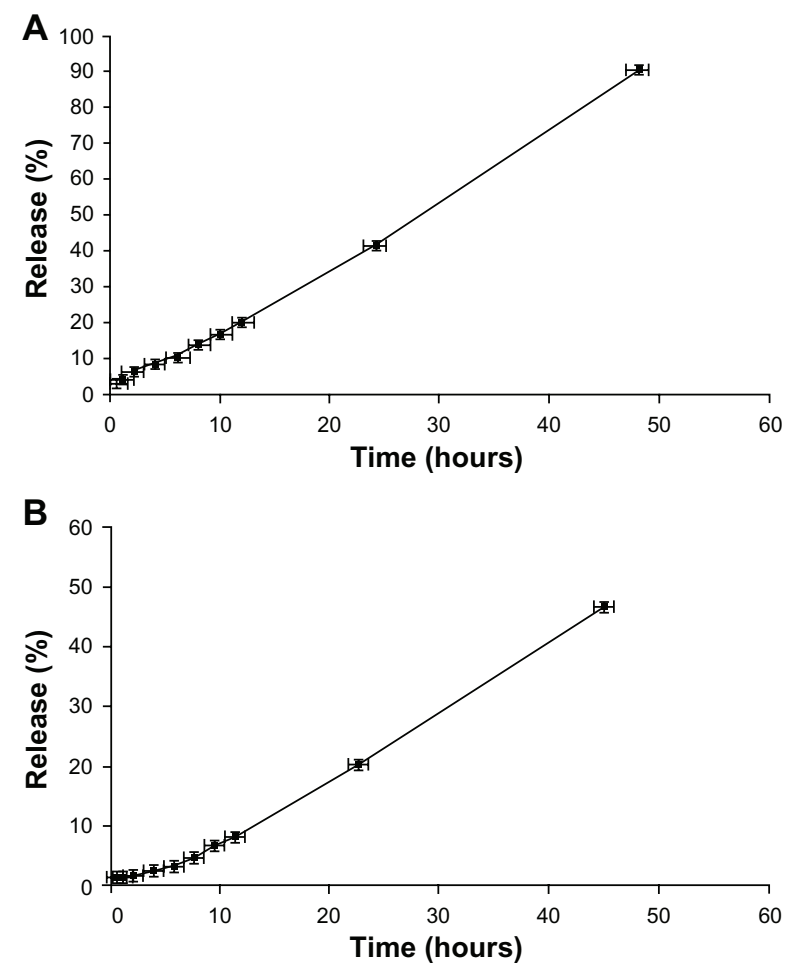

Figure $\mathbf{6}$ In vitro release profile of (A) zerumbone and (B) zerumbone from nanostructured lipid carriers. 
useful carrier with good control of zerumbone release. The zerumbone released from the pure drug dispersion at the end of 48 hours was $90.59 \%$ (1.81 mg).

Drug release from nanoparticles generally takes place by several mechanisms, including surface and bulk erosion, disintegration, diffusion, and desorption. Formulations with higher drug content show higher release rate constants. However, formulations with higher entrapment efficiency show slower and more sustained drug release. ${ }^{58}$ This slow release of drug from nanoparticles is due to homogenous entrapment of the drug, while fast release may be due to a large surface area with a high diffusion coefficient (ie, a small molecular size). Therefore, nanoparticles with a small particle size and consequently a high surface area show rapid release. In NLC, drug release is easier from a formulation with a low lipid content $(5 \%)$. This phenomenon is attributed to formation of a drugenriched shell, which might develop when a low lipid concentration is used. At a higher lipid concentration, a drug-enriched core can develop that will slow down release of the drug.

Another component of the NLC that may affect drug release is the surfactant. A nanosuspension formulation with a higher surfactant concentration (2\%) shows more rapid release of the drug than one with a lower concentration (1\%). It is suggested that the surfactant may fuse with the receiver side, thus altering the barrier properties of the aqueous boundary layer and permeability of the membrane, resulting in high release of the drug from the nanoparticle. In our study, slow release of zerumbone from NLC has been found to occur predominantly by diffusion from the lipid matrix. During the later stages, the release is possibly mediated by both diffusion of the drug and degradation of the lipid matrix itself. The in vitro release profile shows that our ZER-NLC formulation has the capacity to release zerumbone at a sustained rate.

\section{Cytotoxic effect of ZER-NLC} on a leukemic cell line

The cytotoxic effect of nanoparticles is due to their adherence to the cell membrane, internalization, and degradation of byproducts in the cell culture medium or within cells. Most lipid nanoparticles are formulated with glycerides consisting of fatty acids, which are safe and well tolerated by organisms. However emulsifiers, which are also components of these nanoparticles, are potentially toxic. Because the prerequisite for human use is acceptable low toxicity, nanoparticles to be used for parenteral administration must first be tested for their safety. ${ }^{59}$

The in vitro cytotoxicity of zerumbone, ZER-NLC, and free NLC was investigated in a Jurkat T-cell line (J.RT3-T3.5) and
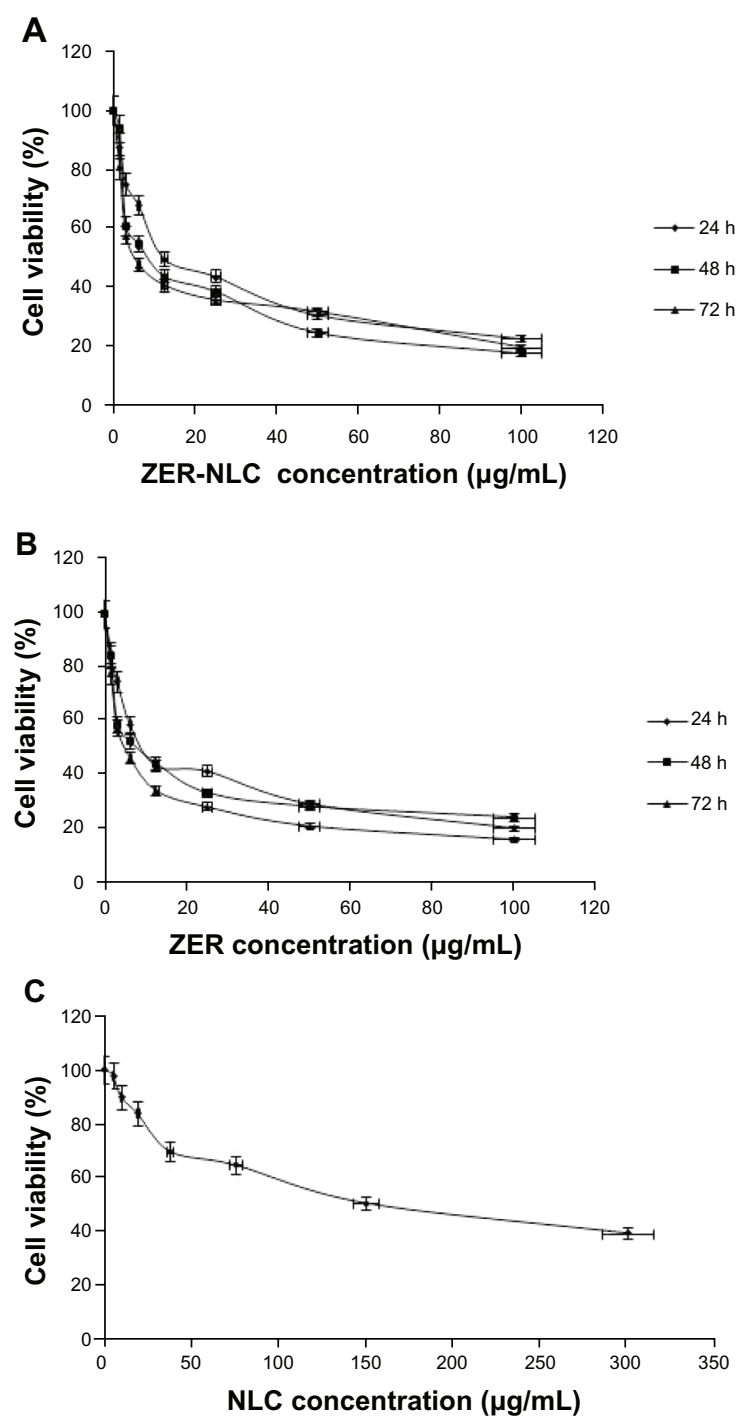

Figure $\mathbf{7}$ Cytotoxicity assay of treated Jurkat cells with $(\mathbf{A})$ zerumbone-loaded nanostructured lipid carriers, (B) zerumbone, and (C) blank nanostructured lipid carriers.

Abbreviations: ZER, zerumbone; ZER-NLC, zerumbone-loaded nanostructured lipid carriers; h, hours.

analyzed by MTT assay (Figure 7). The viability of these human leukemic cells treated with various concentrations of zerumbone, ZER-NLC, and free NLC for 24, 48, and 72 hours decreased significantly $(P<0.05)$ in a dose-dependent manner. Our study shows that the anticancer activity of zerumbone is not affected or impaired by its incorporation into NLC. The $\mathrm{IC}_{50}$ value for zerumbone alone was $11.87 \pm 0.17,8.59 \pm 0.48$, and $5.39 \pm 0.43 \mu \mathrm{g} / \mathrm{mL}$ after 24,48 , and 72 hours of treatment, respectively, while for ZER-NLC it was $12.5 \pm 0.1 \mu \mathrm{g} /$ $\mathrm{mL}, 9.09 \pm 0.14 \mu \mathrm{g} / \mathrm{mL}$, and $5.64 \pm 0.38 \mu \mathrm{g} / \mathrm{mL}$ after 24 , 48 , and 72 hours of treatment, respectively. It is obvious that the cytotoxic effect of ZER-NLC on Jurkat cells was similar to that of free zerumbone at the different time points post treatment. The only possible difference in the mode of action 
between ZER-NLC and zerumbone is that free zerumbone is immediately available to target cells by passive diffusion whereas, for rapid access to zerumbone from ZER-NLC, the nanoparticle must first be internalized via endocytosis or phagocytosis and released into the extracellular space ${ }^{60}$ The release of zerumbone from the nanoparticles can be by fractions of total loaded zerumbone and this allows for prolonged action on the target cells. This certainly makes ZER-NLC more effective for delivery of zerumbone than free zerumbone in the treatment of disease, especially cancer. ${ }^{61}$

The cytotoxicity of nonloaded NLC was also concurrently determined using MTT assay. Blank NLC gave an $\mathrm{IC}_{50}$ of $230.76 \pm 5.55 \mu \mathrm{g} / \mathrm{mL}$ after 72 hours of treatment. This cytotoxic effect of NLC, although minimal, is mainly due to the lecithin and other components, especially the nonionic emulsifier in the formulation. Our results show that the cytotoxic effect of ZER-NLC in Jurkat cells is primarily due to zerumbone.

Inadequate delivery of chemotherapeutic drugs to tumor tissue can lead to regrowth of tumor cells and even development of resistant cells, as well as minimum therapeutic outcomes. ${ }^{62}$ Apart from improving drug dissolution, drug-loaded nanoparticles also have other biological activity, including sustained release and targeting of specific tissues and organs. Nanostructured lipid carriers have other advantages, including flexibility in route of administration, which may be either oral, parenteral, ocular, dermal, or pulmonary. ${ }^{63}$ Thus, the flexibility of administration and potential for targeted therapy make ZER-NLC an important development in clinical medicine for treatment of disease, particularly cancer. ${ }^{64}$

\section{Conclusion}

ZER-NLC were successfully prepared and developed using a high-pressure homogenization technique. Physicochemical characterization showed that the ZER-NLC formulation was relatively stable when stored at $4^{\circ} \mathrm{C}, 25^{\circ} \mathrm{C}$, or $40^{\circ} \mathrm{C}$ for at least one month. The formulation showed sustained-release characteristics and had high cytotoxicity in a human T-cell acute lymphocytic leukemia cell line. The ZER-NLC formulation shows potential as a new delivery system for zerumbone in the treatment of leukemia.

\section{Acknowledgments}

The authors would like to express their sincere appreciation to the Microscopy Unit, the Laboratory of Immunotherapeutic and Vaccines, and the Cancer Research Laboratory, Institute of Bioscience, University Putra Malaysia, for their kind and invaluable assistance in the conduct of this study. They are greatly indebted to the Department of Physics and Chemistry, Faculty of Science, University Putra Malaysia, for providing technical knowledge and an analytical facility. This study was funded by a grant from the Ministry of Science, Technology, and Innovation (5495308).

\section{Disclosure}

The authors report no conflicts of interest in this work.

\section{References}

1. Kitayama T, Yokoi T, Kawai Y, et al. The chemistry of zerumbone. Part 5: Structural transformation of the dimethylamine derivatives. Tetrahedron. 2003;59:4857-4866

2. Kitayama T, Okamoto T, Hill RK, et al. Chemistry of zerumbone. 1. Simplified isolation, conjugate addition reactions, and a unique ring contracting transannular reaction of its dibromide. J Org Chem. 1999;64:2667-2672.

3. Murakami A, Takahashi D, Kinoshita T, et al. Zerumbone, a Southeast Asian ginger sesquiterpene, markedly suppresses free radical generation, proinflammatory protein production, and cancer cell proliferation accompanied by apoptosis: the $\alpha, \beta$-unsaturated carbonyl group is a prerequisite. Carcinogenesis. 2002;23:795-802.

4. Jantan I, Raweh SM, Sirat HM, et al. Inhibitory effect of compounds from Zingiberaceae species on human platelet aggregation. Phytomedicine. 2008;15:306-309.

5. Murakami IA, Takahashi M, Jiwajinda S, Koshimizu K, Ohigashi H. Identification of zerumbone in Zingiber zerumbet Smith as a potent inhibitor of 12-O-tetradecanoylphorbol-13-acetate-induced Epstein-Barr virus activation. Biosci Biotechnol Biochem. 1999;63:1811-1812.

6. Sung B, Murakami A, Oyajobi BO, Aggarwal BB. Zerumbone abolishes RANKL-induced NF-KB activation, inhibits osteoclastogenesis, and suppresses human breast cancer induced bone loss in athymic nude mice. Cancer Res. 2009;69:1477-1484.

7. Al-Zubairi AS, Abdul AB, Yousif M. Effects of zerumbone on cisplatininduced clastogenesis in Sprague-Dawley rats bone marrow cells. Afr J Biotechnol. 2011;10:5414-5417.

8. Gao L, Zhang D, Chen M. Drug nanocrystals for the formulation of poorly soluble drugs and its application as a potential drug delivery system. J Nanopart Res. 2008;10:845-862.

9. Seenivasan A, Panda T, Théodore T. Lovastatin nanoparticle synthesis and characterization for better drug delivery. Open Biotechnol J. 2011;5:28-32.

10. Souto EB, Wissing SA, Barbosa CM, Müller RH. Development of a controlled release formulation based on SLN and NLC for topical clotrimazole delivery. Int J Pharm. 2004;278:71-77.

11. Abbasalipourkabir R, Salehzada A, Rasedee A. Solid lipid nanoparticles as new drug delivery system. Indian J Pharm Sci. 2011;2: 252-261.

12. Junghanns JH, Müller RH. Nanocrystal technology, drug delivery and clinical applications. Int J Nanomedicine. 2008;3:295.

13. Patidar A, Thakur DS, Kumar P, Verma J. A review on novel lipid based nanocarriers. Int J Pharmacol Pharm Sci. 2010;4:30-35.

14. Ioana L, Nicoleta B, Alina M, Aurelia M. The encapsulation effect of UV molecular absorbers into biocompatible lipid nanoparticles. Nanoscale Res Lett. 2011;6:73-82.

15. Shaji J, Jain V. Solid lipid nanoparticles: a novel carrier for chemotherapy. Int J Pharmacol Pharm Sci. 2010;2:8-17.

16. Mistry SN, Patel PK, Bharadia PD, Pandya VM, Modi DA. Novel drug delivery system for lipophilic agents: solid lipid nanoparticles. J Pharm Cosmetol. 2011;1:76-89.

17. Pardeike J, Hommoss A, Müller RH. Lipid nanoparticles (SLN, NLC) in cosmetic and pharmaceutical dermal products. Int J Pharm. 2009;366:170-184. 
18. Müller RH, Mäder K, Gohla S. Solid lipid nanoparticles (SLN) for controlled drug delivery - a review of the state of the art. Eur J Pharm Biopharm. 2000;50:161-177.

19. Bhatt DA, Pethe AM. Lipid technology - a promising drug delivery system for poorly water soluble drugs. International Journal of Pharma Research. 2010;2.

20. Hughes GA. Nanostructure-mediated drug delivery. Nanomedicine. 2005;1:22-30.

21. Müller RH, Radtke M, Wissing SA. Solid lipid nanoparticles (SLN) and nanostructured lipid carriers (NLC) in cosmetic and dermatological preparations. Adv Drug Deliv Rev. 2002;54 Suppl 1:S131-S155.

22. Müller RH, Radtke M, Wissing SA. Nanostructured lipid matrices for improved microencapsulation of drugs. Int J Pharm. 2002;242: 121-128.

23. Mehanna M, Motawaa A, Samaha M. Pharmaceutical particulate carriers: lipid-based carriers. Natl J Physiol Pharm Pharmacol. 2012;2:10-22.

24. Souto EB, Muller RH. The use of SLN and NLC as topical particulate carriers for imidazole antifungal agents. Pharmazie. 2006;61:431-437.

25. Müller RH, Mäder K, Lippacher A, Jenning V. Solid-liquid (semi-solid) liquid particles and method of producing highly concentrated lipid particle dispersions. German Patent Application. 2000;199(45,203.2).

26. Abdelwahab SI, Abdul AB, Mohan S, et al. Zerumbone induces apoptosis in T-acute lymphoblastic leukemia cells. Leuk Res. 2011;35:268-271.

27. Mukherjee S, Ray S, Thakur RS. Solid lipid nanoparticles: a modern formulation approach in drug delivery system. Indian J Pharm Sci. 2009;71:349-358.

28. How CW, Abdullah R, Abbasalipourkabir R. Physicochemical properties of nanostructured lipid carriers as colloidal carrier system stabilized with polysorbate 20 and polysorbate 80 . Afr J Biotechnol. 2011;10:1684-1689.

29. Venkatesh T, Reddy AK, Maheswari JU, Dalith MD, Kumar CK. Nanosuspensions: ideal approach for the drug delivery of poorly water soluble drugs. Der Pharmacia Lettre. 2011;3:203-213.

30. Xin H, Chen L, Gu J, et al. Enhanced anti-glioblastoma efficacy by PTX-loaded PEGylated poly ( $\varepsilon$-caprolactone) nanoparticles: in vitro and in vivo evaluation. Int J Pharm. 2010;402:238-247.

31. de Waard H, Grasmeijer N, Hinrichs WL, Eissens AC, Pfaffenbach PF, Frijlink HW. Preparation of drug nanocrystals by controlled crystallization: application of a 3-way nozzle to prevent premature crystallization for large scale production. Eur J Pharm Sci. 2009;38:224-229.

32. Wa Kasongo K, Shegokar R, Müller RH, Walker RB. Formulation development and in vitro evaluation of didanosine-loaded nanostructured lipid carriers for the potential treatment of AIDS dementia complex. Drug Dev Ind Pharm. 2011;37:396-407.

33. Eid EM, Abdul AB, Suliman FE, Sukari MA, Rasedee A, Fatah SM. Characterization of the inclusion complex of zerumbone with hydroxypropyl- $\beta$-cyclodextrin. Carbohydr Polym. 2011;83: $1707-1714$.

34. Xia Q, Wang H. Preparation and characterization of coenzyme Q10loaded nanostructured lipid carriers as delivery systems for cosmetic component. Nanotech. 2010;3:498-501. Available from: http://www. nsti.org/procs/Nanotech2010v3/7/T40.610. Accessed June 9, 2013.

35. Hu FQ, Jiang SP, Du YZ, Yuan H, Ye YQ, Zeng S. Preparation and characteristics of monostearin nanostructured lipid carriers. Available from: http://materiales.azc.uam.mx/area/Ingenieria_ Materiales/investigaci\%C3\%B3n/2261204/cuan\%20calif/Cuan $\% 20$ TechConWo2010/CD/Nanotech2010/pdf/1469.pdf. Accessed June 9, 2013.

36. Mulla AS, Shetty NS, Panchamukhi SI, Khazi IA. Formulation, characterization and in vitro evaluation of novel thienopyrimidies and triazolothienopyrimidies loaded solid lipid nanoparticles. International Journal of Research in Ayurveda and Pharmacy. 2010;1:192-200.

37. Madishetti SK, Palem CR, Thatipamula RP, Panakanti PK, Yamsani MR. Development of domperidone bilayered matrix type transdermal patches: physicochemical, in vitro and ex vivo characterization. Daru. 2010;18:221-229.
38. Saboktakin MR, Tabatabaie RM, Maharramov A, Ramazanov MA. Synthesis and characterization of biodegradable thiolated chitosan nanoparticles as targeted drug delivery system. J Nanomed Nanotechnol. 2011;S4:001.

39. Saboktakin MR, Tabatabaie RM, Maharramov A, Ramazanov MA. Synthesis and in vitro evaluation of thiolated chitosan-dextran sulfate nanoparticles for the delivery of letrozole. J Pharm Educ Res. 2010;1: 62-67.

40. Zeng Z, Lin J, Li H, et al. Effect of the matrices and penetration enhancers in elemene transdermal drug delivery system. Afr J Pharm Pharmacol. 2011;5:879-886.

41. Derakhshandeh K, Soheili M, Dadashzadeh S, Saghiri R. Preparation and in vitro characterization of 9-nitrocamptothecin-loaded long circulating nanoparticles for delivery in cancer patients. Int J Nanomedicine. 2010;5:463-471.

42. Won HJ, Han CH, Kim YH, et al. Induction of apoptosis in human acute leukemia Jurkat $\mathrm{T}$ cells by Albizzia julibrissin extract is mediated via mitochondria-dependent caspase-3 activation. $J$ Ethnopharmacol. 2006;106:383-389.

43. Fang YP, Lin YK, Su YH, Fang JY. Tryptanthrin-loaded nanoparticles for delivery into cultured human breast cancer cells, MCF7: the effects of solid lipid/liquid lipid ratios in the inner core. Chem Pharm Bull. 2011;59:266-271.

44. De Jong WH, Paul JA. Drug delivery and nanoparticles: applications and hazards. Int J Nanomedicine. 2008;3:133-149.

45. Burgess DJ, editor. Colloids and Colloid Drug Delivery Systems. 3rd ed. London, UK: Encyclopedia of Pharmaceutical Technology; 2006.

46. Thatipamula RP, Palem CR, Gannu R, Mudragada S, Yamsani MR. Formulation and in vitro characterization of domperidone loaded solid lipid nanoparticles and nanostructured lipid carriers. Daru. 2011;19:23-32.

47. Souto EB, Muller RH. Lipid nanoparticles (solid lipid nanoparticles and nanostructured lipid carriers) for cosmetic, dermal, and transdermal applications. Drugs Pharm Sci. 2007;166:213.

48. zur Mühlen A, Schwarz C, Mehnert W. Solid lipid nanoparticles (SLN) for controlled drug delivery - drug release and release mechanism. Eur J Pharm Biopharm. 1998;45:149-155.

49. Jenning V, Thünemann AF, Gohla SH. Characterisation of a novel solid lipid nanoparticle carrier system based on binary mixtures of liquid and solid lipids. Int J Pharm. 2000;199:167-177.

50. Wan F, You J, Sun Y, Xing GZ, Fu DC. Studies on PEG-modified SLNs loading vinorelbine bitartrate (1): preparation and evaluation in vitro. Int J Pharm Pharm Sci. 2008;359:104-110.

51. Kuntsche J, Westesen K, Drechsler M, Koch HJ, Bunjes H. Supercooled smectic nanoparticles: a potential novel carrier system for poorly water soluble drugs. Pharm Res. 2004;21:1834-1843.

52. Müller RH, Radtke M, Wissing SA. Solid lipid nanoparticles and nanostructured lipid carriers. In: Nalwa HS, editor. Encyclopedia of Nanoscience and Nanotechnology. Valencia, CA: American Scientific Publishers; 2004.

53. Freitas C, Muller RH. Correlation between long-term stability of solid lipid nanoparticles (SLN) and crystallinity of the lipid phase. Eur $J$ Pharm Biopharm. 1999;47:125-132.

54. Akhayachatra C. Development of lipid nanoparticles for anticancer drug delivery systems. Bangkok, Thailand: Faculty of Pharmacy, Silpakorn University; 2009.

55. Floyd AG. Top ten considerations in the development of parenteral emulsions. Pharm Sci Technolo Today. 1999;2:134-143.

56. Joshi M, Patravale V. Nanostructured lipid carrier (NLC) based gel of celecoxib. Int J Pharm. 2008;346:124-132.

57. Gambhire MS, Bhalekar MR, Gambhire VM. Simvastatin loaded solid lipid nanoparticles: formulation optimization using box behnken design, characterization and in vitro evaluation. Curr Pharm Res. 2011;1: 157-164.

58. Jithan AV, Swathi M. Development of topical diclofenac sodium liposomal gel for better anti-inflammatory activity. Int J Pharm Sci Nanotechnol. 2010;3:986-992. 
59. Bondì ML, Craparo EF, Giammona G, et al. Nanostructured lipid carriers-containing anticancer compounds: preparation, characterization, and cytotoxicity studies. Drug Deliv. 2007;14:61-67.

60. Chen H, Kim S, Li L, Wang S, Park K, Cheng J. Release of hydrophobic molecules from polymer micelles into cell membranes revealed by Förster resonance energy transfer imaging. Proc Natl Acad Sci U S A. 2008;105:6596-6601.

61. Dong Y, Feng S. In vitro and in vivo evaluation of methoxy polyethylene glycol-polylactide (MPEG-PLA) nanoparticles for small-molecule drug chemotherapy. Biomaterials. 2007;28:4154-4160.
62. Monteagudo E, Gándola Y, González L, Bregni C, Carlucci AM. Development, characterization, and in vitro evaluation of tamoxifen microemulsions. J Drug Deliv. 2012;2012:236713.

63. D’Aquino R, Harper T, Roman VC, editors. Nanotechnology Opportunity Report. 2nd ed. London, UK: Cientificas; 2003.

64. Shenoy VS, Vijay IK, Murthy RS. Tumour targeting: biological factors and formulation advances in injectable lipid nanoparticles. J Pharm Pharmacol. 2005;57:411-421.
International Journal of Nanomedicine

\section{Publish your work in this journal}

The International Journal of Nanomedicine is an international, peerreviewed journal focusing on the application of nanotechnology in diagnostics, therapeutics, and drug delivery systems throughout the biomedical field. This journal is indexed on PubMed Central, MedLine, CAS, SciSearch $\AA$, Current Contents ${ } /$ Clinical Medicine,

\section{Dovepress}

Journal Citation Reports/Science Edition, EMBase, Scopus and the Elsevier Bibliographic databases. The manuscript management system is completely online and includes a very quick and fair peer-review system, which is all easy to use. Visit http://www.dovepress.com/ testimonials.php to read real quotes from published authors.

Submit your manuscript here: http://www.dovepress.com/international-journal-of-nanomedicine-journal 